\title{
Grating test of contrast sensitivity in patients with Minamata disease
}

\author{
KAZUO MUKUNO, SATOSHI ISHIKAWA, AND RYOICHI OKAMURA* \\ From the Department of Ophthalmology, School of Medicine, Kitasato University, Kanagawa, \\ and the *Department of Ophthalmology, School of Medicine, Kumamoto University, \\ Kumamoto, Japan
}

SUMMARY Thirty cases of Minamata disease caused by methyl mercury poisoning with the lesiom mainly at the occipital cortex were selected and their spatial contrast sensitivity of vision was. examined by the Arden grating chart. At the same time their visual acuity, visual field, and visual evoked cortical potential (VECP) were also investigated.

In all cases the results of the Arden test indicated abnormality. Poor results were obtained at higher frequencies of the gratings. VECP elicited by grating pattern reversal stimulus was undertaken in 12 cases out of the 30 . The results revealed abnormality almost equal to that shown by the Arden test. Seven out of the 12 cases showed no VECP response. The other 5, giving a response, showed abnormality: when the size of the grating became smaller at higher frequencies, the VECP paused or was not recorded, whereas at low frequencies it was recorded. This finding was in good agreement with the results of the Arden test. Visual acuity and visual field tests were less sensitive in detecting abnormality. The Arden chart is a sensitive clinical tool for patients with lesions at the cerebral cortex. Furthermore, the test can be used for screening patients who may have come in contact with organic mercury.

For the past several years spatial contrast sensitivity, i.e., grating visual acuity, has been studied in various ocular diseases. Recently the Arden grating chart $^{1}$ has been produced as a simple clinical test for measurement of contrast sensitivity. Its clinical usefulness has been introduced for patients with glaucoma, ${ }^{2}$ retrobulbar optic neuritis, ${ }^{3}$ and macular diseases. ${ }^{4}$ With the exception of a few reports. ${ }^{5}$ no descriptions have been given in relation to diseases of the visual cortex.

The use of grating acuity in patients with cortical lesions has been introduced. Minamata disease, which is caused by methyl mercury poisoning, is particularly suitable for showing abnormality with the Arden chart, since the lesion is located mainly at the occipital cortex, thus producing concentric narrowing of the visual fields with almost normal visual acuity.

In the present study 30 patients with typical Minamata disease were selected, and their spatial contrast sensitivity, visual acuity, visual field, and

Correspondence to Dr Kazuo Mukuno (Department of Ophthalmology), 1-15-1 Kitasato, Sagamihara City, Kanagawa 228, Japan. visually evoked cortical response were examined. The Arden chart was used, and its clinical usefulness in detecting abnormalities in the visual system in Minamata disease could be demonstrated.

\section{Materials and methods}

\section{SELECTION OF PATIENTS}

Diagnosis of the patients was established in accordance with the diagnostic criteria presented by the Minamata Disease Project members of Kumamoto University. ${ }^{6}$ All patients had had heavy contact with methyl mercury from the clinical and epidemiological points of view. Generally, symptoms included peripheral neuropathy, cerebellar ataxia, dysarthria, bilateral peripheral constriction of visual fields, and hearing disturbances. These accorded well with the signs and symptoms of Hunter-Russell syndrome.? The onset of the disease was mostly 15 to 25 years ago, and the patients had been examined in hospital for a certain period of time for the establishment of the diagnosis. Since then they have been followed up. Their symptoms and the signs elicited when the tests were performed are shown in Table 1. These 
Table 1 Clinical manifestations of both ophthalmological and neurological examinations of group 2 patients. The total score of the Arden grating test is included as well as the results of the VECP examination

\begin{tabular}{|c|c|c|c|c|c|c|c|c|c|c|c|}
\hline \multirow[b]{2}{*}{ Case } & \multirow[b]{2}{*}{$\begin{array}{l}\text { Age } \\
(y r)\end{array}$} & \multirow[b]{2}{*}{$\operatorname{Sex}$} & \multicolumn{5}{|c|}{ Ophthalmological examinations } & \multicolumn{4}{|c|}{ Neurological examinations } \\
\hline & & & $\begin{array}{l}\text { Visual } \\
\text { acuity } \\
(R / L)\end{array}$ & $\begin{array}{l}\text { Right visual } \\
\text { fields } \\
\text { (temporal/ } \\
\text { nasal) } \\
\text { in degrees }\end{array}$ & $\begin{array}{l}\text { Total score } \\
\text { of Arden } \\
\text { grating test } \\
\text { (both eyes) }\end{array}$ & $\begin{array}{l}\text { Visually evoked } \\
\text { cortical response } \\
(V E C P)\end{array}$ & $\begin{array}{l}\text { Bilateral } \\
\text { incipient } \\
\text { cataracts }\end{array}$ & $\begin{array}{l}\text { Peripheral } \\
\text { neuropathy }\end{array}$ & $\begin{array}{l}\text { Cere- } \\
\text { bellar } \\
\text { ataxia }\end{array}$ & $\begin{array}{l}\text { Hearing } \\
\text { disturb- } \\
\text { ance }\end{array}$ & Other remarks \\
\hline 1 & 68 & $\mathbf{F}$ & $0.6 / 0 \cdot 5$ & $75 / 53$ & 97 & Reduced amplitude & No & + & - & + & \\
\hline 2 & 72 & $\mathbf{M}$ & $0.9 / 0.9$ & $52 / 40$ & 92 & Reduced amplitude & Yes & + & - & - & \\
\hline 3 & 74 & $\mathbf{F}$ & $0.8 / 0.8$ & $75 / 53$ & 104 & Unrecordable & Yes & + & + & + & $\begin{array}{l}\text { Dysarthria, tremor, } \\
\text { muscle weakness }\end{array}$ \\
\hline 4 & 56 & $\mathbf{F}$ & $1 \cdot 2 / 1 \cdot 2$ & $70 / 53$ & 105 & Unrecordable & No & + & + & + & Dysarthria, tremor \\
\hline 5 & 73 & $\mathbf{F}$ & FC*/0.8 & $72 / 60$ & 101 & Unrecordable & Yes & + & - & 一 & \\
\hline 6 & 58 & $\mathbf{M}$ & $1 \cdot 2 / 1 \cdot 2$ & $98 / 60$ & 78 & Reduced amplitude & No & \pm & 一 & 一 & \\
\hline 7 & 68 & $\mathbf{F}$ & $0 \cdot 8 / 0 \cdot 8$ & $77 / 50$ & 95 & Unrecordable & Yes & + & 一 & 一 & \\
\hline 8 & 62 & $\mathbf{F}$ & $0.9 / 1.0$ & $95 / 65$ & 97 & Reduced amplitude & No & + & + & \pm & $\begin{array}{l}\text { Mental disturbance } \\
\text { (mild) }\end{array}$ \\
\hline 9 & 76 & $\mathbf{F}$ & $0.6 / 0.6$ & $78 / 52$ & 112 & Unrecordable & Yes & + & - & 一 & Tremor \\
\hline 10 & 62 & $\mathbf{F}$ & $1 \cdot 5 / 1 \cdot 2$ & $80 / 60$ & 93 & Unrecordable & No & + & - & + & \\
\hline 11 & 25 & $\mathbf{F}$ & $0.9 / 0.9$ & $50 / 38$ & 98 & Unrecordable & No & 一 & + & \pm & $\begin{array}{l}\text { Congenital type } \\
\text { mental retardation }\end{array}$ \\
\hline 12 & 25 & $\mathbf{M}$ & $0.9 / 1.0$ & $60 / 35$ & 93 & Reduced amplitude & No & - & + & 一 & $\begin{array}{l}\text { Congenital type } \\
\text { dysarthria } \\
\text { Mental retardation }\end{array}$ \\
\hline
\end{tabular}

*FC = finger counting with senile macular degeneration

clinical manifestations were almost stable after the exacerbation of the diseases. Patients who were not co-operative during the examinations were excluded.

The Arden grating test was undertaken twice, once on 10 July 1978 and again on 28 February 1980 with 2 groups of patients, who are tentatively divided in group 1 and group 2. Group 1 included 6 males and 12 females ranging in age from 36 to 71 with a mean age of 54 . Group 2 included 3 males and 9 females ranging in age from 25 to 76 with a mean age of 60 . The neurological manifestations of the 2 groups were almost identical. The results of clinical tests of group 2 are listed in Table 1. Two cases of congenital Minamata disease have been included in group 2.

\section{OPHTHALMOLOGICAL TESTS}

All cases underwent visual acuity measurement with a Landolt ring correcting the refraction, the Arden grating test, a visual field test by Goldmann perimeter, and routine ophthalmological examinations. These were carried out by the same ophthalmologists, special perimetrist, and orthoptist for both groups. Except for incipient cataracts, patients with eye diseases such as severe cataracts, glaucoma, and retinal diseases were carefully excluded from the present groups. Cases with reduced visual acuity caused by ocular disease were also omitted.

Visually evoked cortical response. The visually evoked cortical response (VECP) was tested in group 2. The recording was made with a Medelec (Visual Stimulator, England) pattern reversal stimulator and amplifier as well as an averager with the electrodes placed at $\mathrm{OZ}$ and PZ. The ear lobe was used as reference. Vertical black and white lines of pattern reversal stimuli were made on a television screen $(30 \times 40 \mathrm{~cm})$, and the patient was asked to look at the small target ( 2 degrees) placed at the centre of the oscilloscope. The distance between the patient and the oscilloscope was $2 \mathrm{~m}$. The contrast of the pattern was $50 \%$, and the spatial frequency was alternated among $0.5,1 \cdot 0$, $2 \cdot 0,4 \cdot 0$, and $8 \cdot 0$ cycles per degree, which were almost similar to the spatial frequency of the Arden chart. Fixation of the patients was carefully observed. VECP was mostly stable at the $\mathrm{OZ}$ electrode, so this result will be mentioned below. The time to peak of positive peak 1 and the amplitude from positive peak 1 and negative peak 2 were measured. 

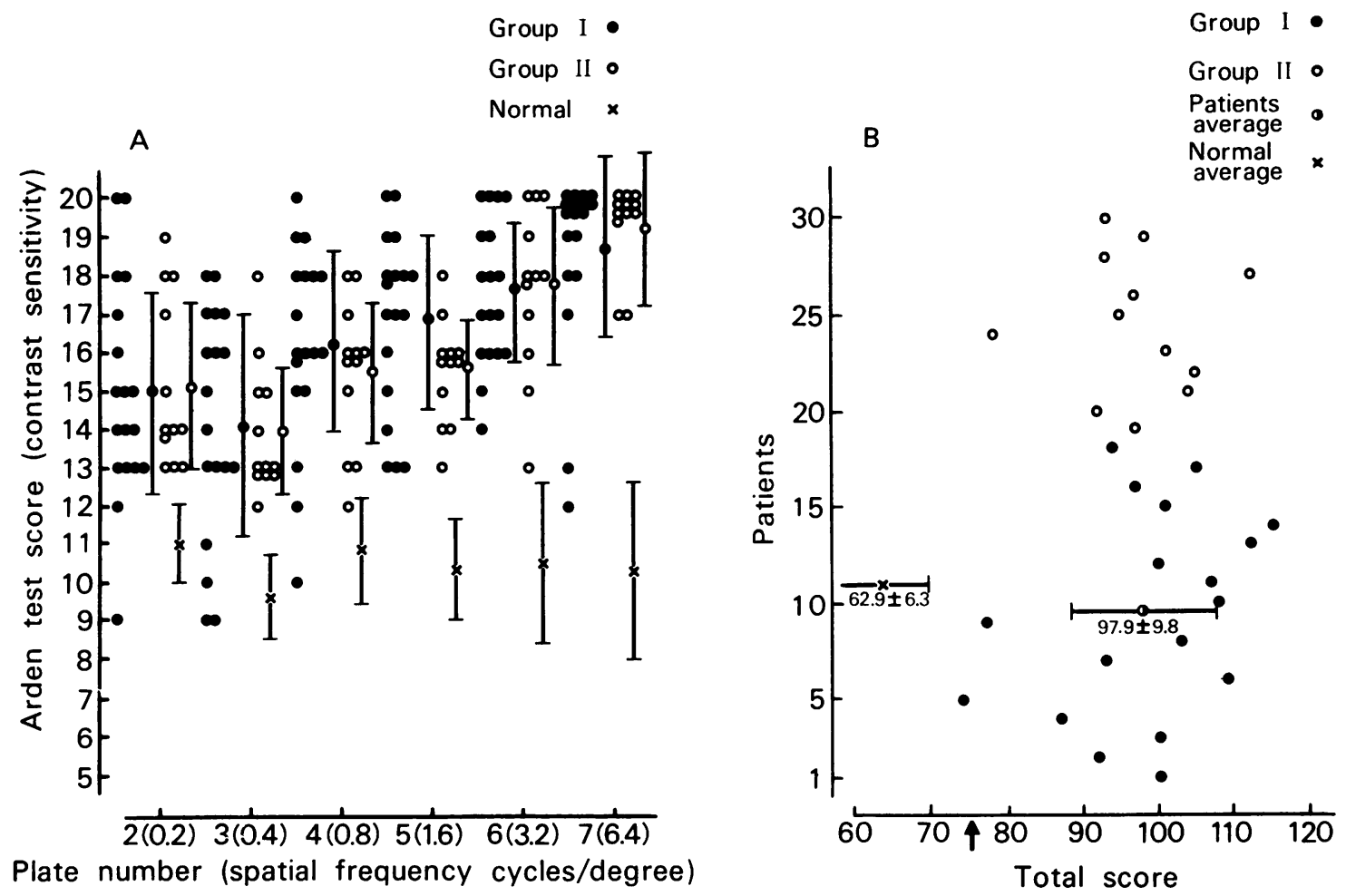

Fig. 1A Comparison between spatial frequency (plate number) and contrast sensitivity (Arden test score) of group 1 patients $(\mathrm{O})$, group 2 patients $(\mathrm{O})$, and normal subjects. (X). Vertical bars denote mean and standard deviation. B: Total score of the Arden grating test against patients. The values of normal controls and patients were $62 \cdot 9 \pm 6 \cdot 3$ and $97 \cdot 9 \pm 9 \cdot 8$, respectively. Upper limit of normal score arrowed.

The amplitude reduction rate against different spatial frequencies was calculated by using the VECP obtained from $0.5 \mathrm{c} / \mathrm{s}$ as a standard. Responses to other frequencies were expressed in percentages. For the VECP controls 7 healthy doctors with a mean age of 34 were used at the same time as the measurement and the same analyses were made.

Arden grating test. The tests were carried out by the same ophthalmologists in both examination groups. The original method described by Arden ${ }^{2}$ was employed. All patients underwent the examination at least 3 times with their vision corrected. At least 30 minutes were spent on one patient. As controls, 22 healthy male subjects aged 40 to 65 with a mean age of 51 were used. No differences between the right and left eyes were seen in either the patients or the controls. Better results were obtained with both eyes open. Therefore these data were used for comparison. Afterwards correlations of the results of the Arden test, visual acuity, visual field, and VECP were made, and correlation coefficients were calculated.

\section{Results}

\section{PATIENTS}

The clinical results of the ophthalmological and neurological examinations obtained from group 2 are listed in Table 1. According to the neurological examinations these patients generally showed peripheral neuropathy, cerebellar ataxia, hearing disturbances, and other signs and symptoms.

\section{ARDEN GRATING TESTS}

The results obtained from group 1 and group 2 patients are shown in Fig. 1A. The contrast sensitivity (Arden test score) against spatial frequency cycles per degree (plate number) is given. Means and standard deviations for each plate number are shown. The control results (X) are also listed. The difference between the patients and the controls at each plate number was significant $(P<0.01)$. The difference was smaller for lower spatial frequencies. Fig. 1B shows, for patients with 1 to 30 , the total score of the Arden chart. Almost identical results 
were obtained from group 1 and group 2. The upper limit of the normal controls was 75 as shown by the arrow. The mean total scores were $62 \cdot 9 \pm 6 \cdot 3$

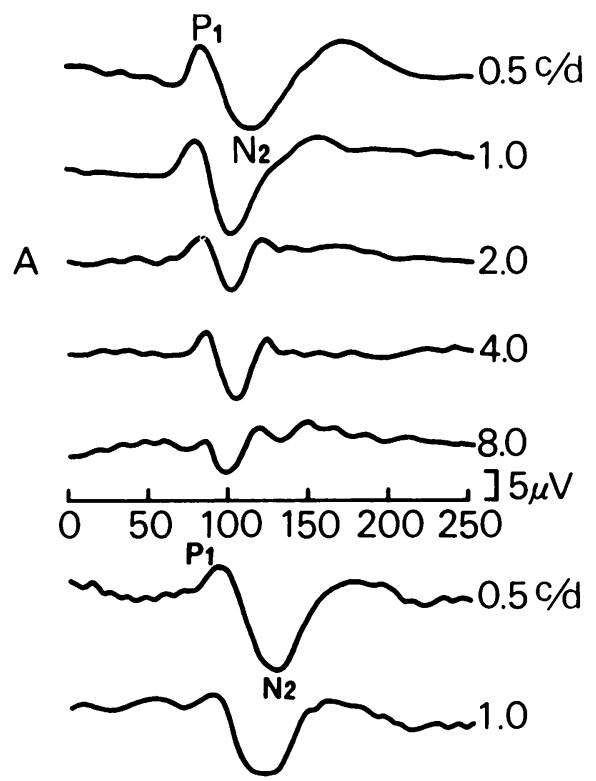

B
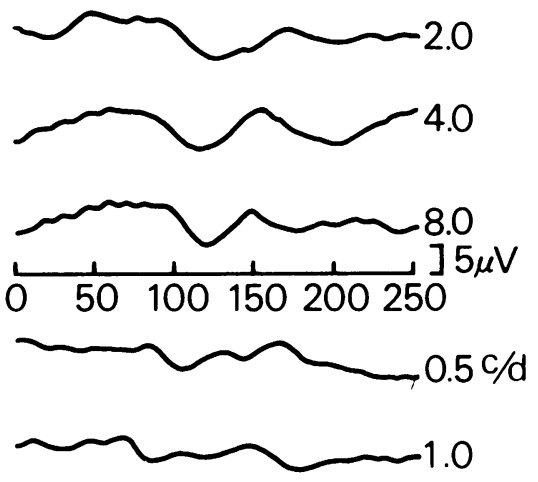

C
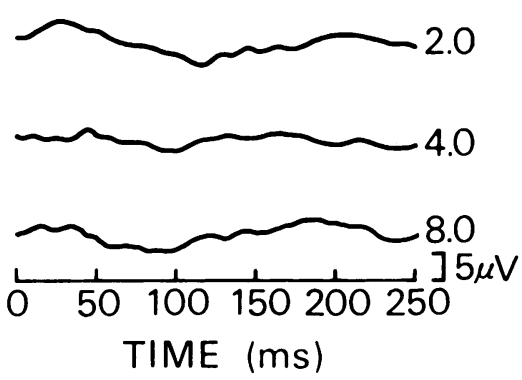

Fig. 2A VECP obtained from a normal subject with stimulus frequencies of $0.5,1,2,4$, and $8 \mathrm{c} / \mathrm{deg}$. B: VECP obtained from a Minamata disease patient at the same frequency stimuli. C: VECP obtained from another case of Minamata disease. and $97.9 \pm 9.8$ in the controls and the patients, respectively. The difference was significant with $\mathbf{P}<0.01$. The data indicated that all the patients were abnormal by the Arden grating test.

VECP

Typical recordings obtained from normal controls and patients are given in Figs. 2A (normal), B (patient), and C (patient).

The VECP was recorded in only 5 out of the 12 cases examined. In the remaining 7 it was unrecordable. The VECP of the patients was further analysed. The time to peak of $P_{1}$ against stimulus spatial frequency of the controls $(\mathrm{X})$ is plotted in Fig. 3A. The time to peak of the patients tended to be prolonged. The rate of amplitude reduction in percentage against stimulus spatial frequency is listed in Fig. 3B. In 4 cases out of 5 the amplitude dropped to zero at $2 \mathrm{c} / \mathrm{deg}$ in case 6 and at $4 \mathrm{c} / \mathrm{deg}$ in 3 other cases. In 1 case it declined to zero at $8 \mathrm{c} / \mathrm{deg}$. These data indicated that all patients had abnormal VECP with an amplitude reduction of $P_{1}$. Except for 1 subject this was not seen in the controls.

\section{CORRELATIONS}

The correlations between the Arden grating test and other ophthalmological parameters, such as visual acuity, visual fields, and VECP were determined. The results are given in Fig. 4 with visual acuity shown in $4 \mathrm{~A}$, visual field in $4 \mathrm{~B}$, and VECP in $4 \mathrm{C}$. No correlation was found between the total Arden score and visual acuity $(r=-0 \cdot 16)$. Nor was there any correlation between the total Arden score and the temporal visual field $(r=0 \cdot 25)$. Furthermore, no correlations were seen in the nasal and upper and lower visual fields. The comparison between the total Arden score and 50\% reduction of VECP-P ${ }_{1}$ amplitude are given in Fig. 4C. The 7 cases with no response are designated as zero, and the other 5 cases with responses out of group 2(O) and the normal controls (X) had a statistically significant correlation $(\mathrm{P}<0.001)(\mathrm{r}=0.85, \mathrm{y}=-0 \cdot 17 \mathrm{x}+$ 17.63). These results indicated that the detection of abnormality could be best accomplished by VECP and the Arden grating test in patients with methyl mercury poisoning.

\section{Discussion}

Detection of abnormalities occurring in the visual system as a result of the methyl mercury intoxication of Minamata disease was best demonstrated by the Arden grating test and by the VECP.

The patients in this study had the typical HunterRussell syndrome both clinically and epidemiologically. Cases with unreliable answers to each test 
were excluded, and repeated examinations had good reproducibility. This means that the selection of the patients was accurate and that the tests were reliable. Since the vision was corrected by lenses in all tests, the effects of refraction on spatial frequency could be excluded. Cases with any ophthalmological diseases other than incipient cataracts were not included. Therefore this influence can also be excluded.

According to previous reports, the lesions of Minamata disease are located mainly at the visual cortex. ${ }^{8}$ On the other hand the lateral geniculate body, optic nerve, and retina were reported to be normal. Therefore the abnormality could be located
Fig. 3A $P_{1}$ time to peak (ms) against stimulus spatial frequency of VECP in normal subjects $(X)$ and patients. Prolongation of latency in the patients existed. B: Rate of $P_{1}$-amplitude reduction in percent of VECP against stimulation spatial frequency in normal subjects (X) and patients.
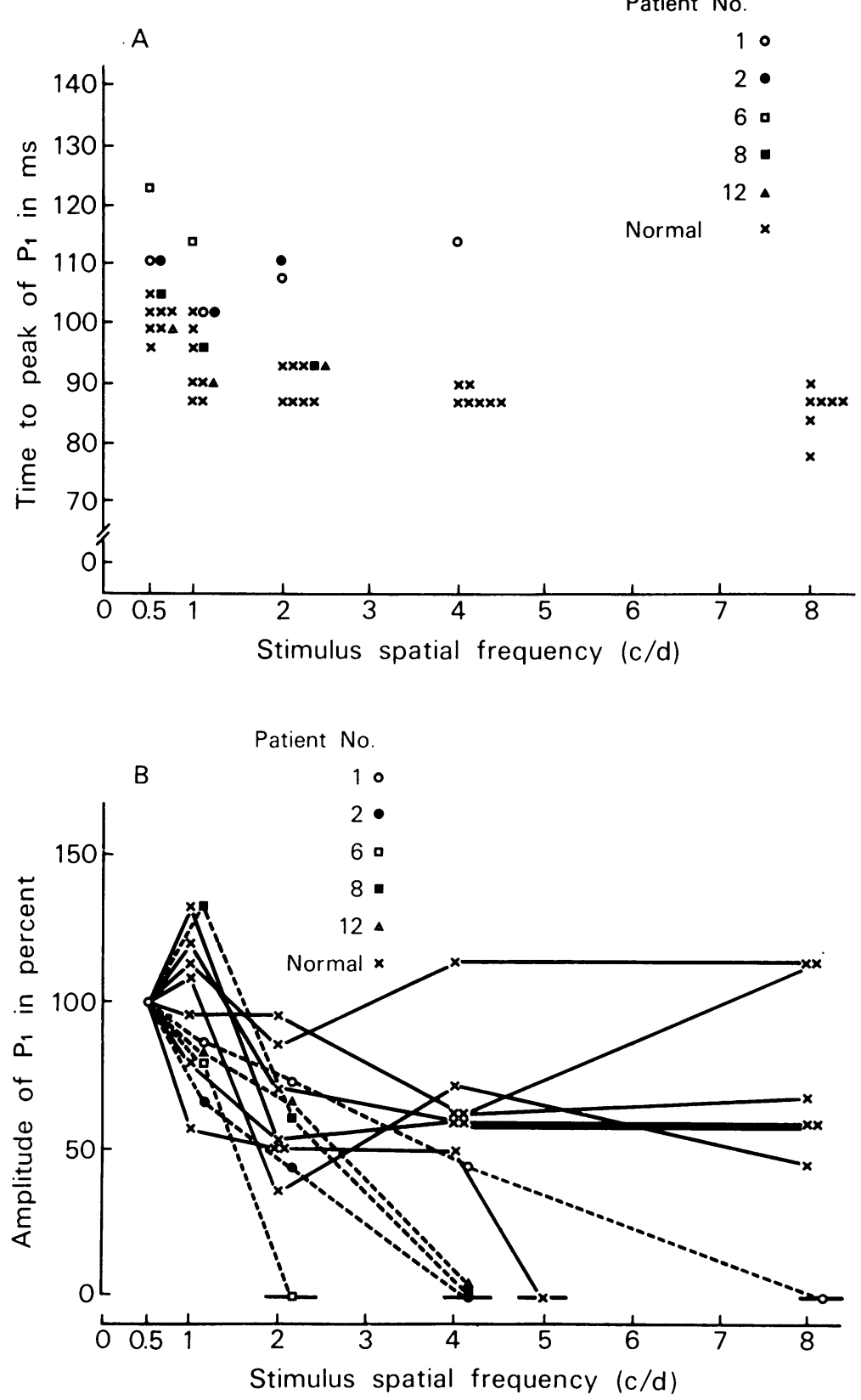

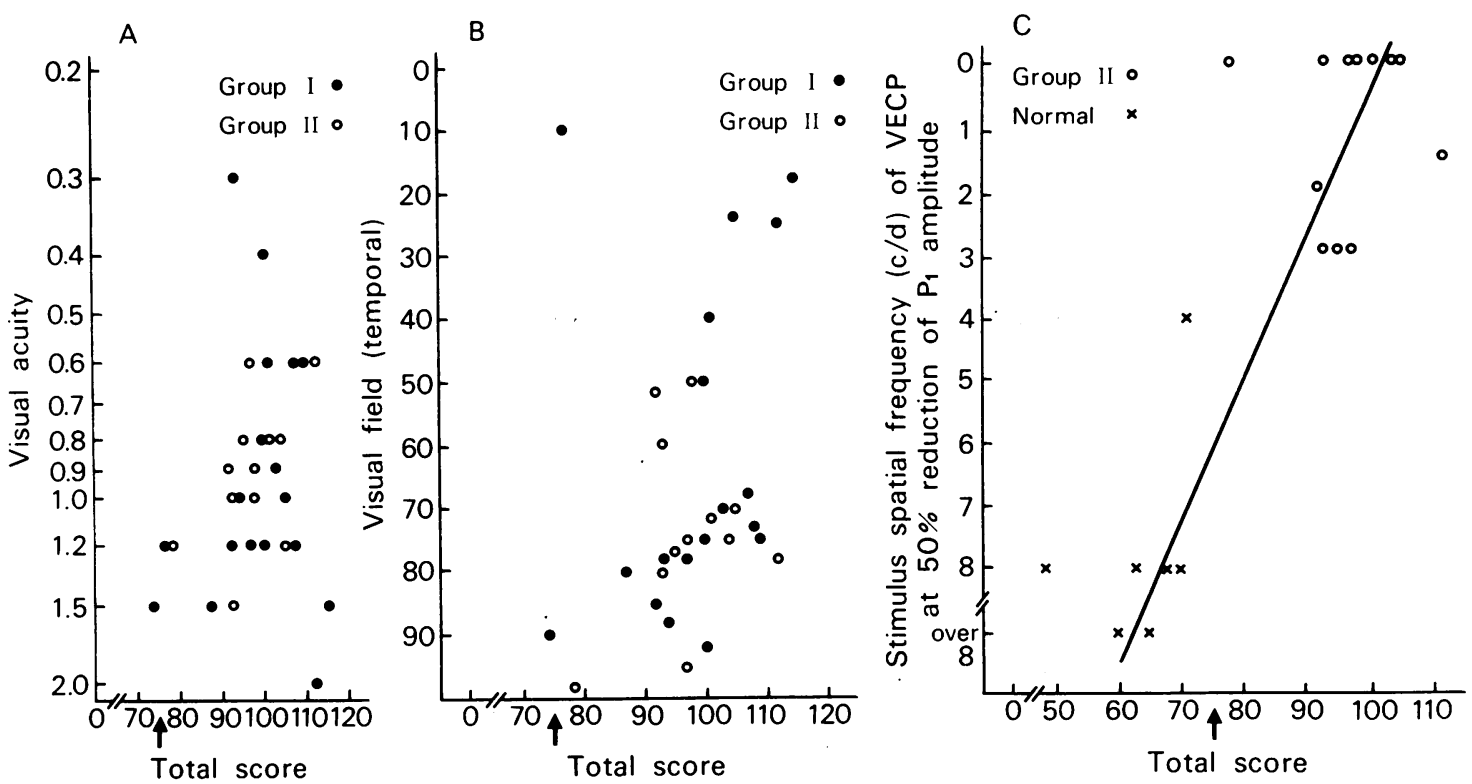

Fig. 4A Correlation between visual acuity (both eyes open) and the total Arden grating test score $(r=-0 \cdot 16)$.

B: Correlation between visual field (temporal) of the better eye and the total Arden grating test score $(r=0 \cdot 25)$.

C: Stimulation spatial frequency of VECP calculated at $50 \%$ reduction of $P_{1}$ amplitude against total score in normal subjects $(\mathrm{X})$ and patients $(\mathrm{O})\left(r=0 \cdot 85, y_{1}=-0 \cdot 17 x+17 \cdot 63\right)$.

at the visual cortex. Concentric narrowing of the visual field is an important finding in HunterRussell syndrome, but it is not a typical finding in all cases. Furthermore, this is often influenced by the psychological condition of the patient. Constant results among patients and good reproducibility of the abnormality indicated that the Arden grating test could be substituted for the visual field test. Good correlation was seen between the total score of the Arden test and VECP. All cases showed the involvement at the higher spatial frequency of the Arden test and of VECP. The involvement must be located at the visual cortex. By combining VECP and the Arden test we could exclude visual field constriction induced by a psychogenic factor even in the cases of Minamata disease.

The effects of age on spatial contrast sensitivity have to be considered. A recent report ${ }^{9}$ has indicated that the total score increased as the age advanced. The same observation was also made by Derefeldt et al. ${ }^{10}$ But the control data obtained from agematched subjects never exceeded 75. When 12 (2 SD) was added to the mean value of the total score in the present study, the results came to 75 . If we set the maximum value at 80 , the detection of abnormality in Minamata disease was more than $90 \%$. Therefore the effects of age were not encountered in the present study.
Recent evidence ${ }^{11}$ showed that the total Arden score was more than 80 in patients who had vascular lesions at both the occipital and parietal cortices. In patients with unilateral occipital lesions alone the number was less than 80 . There is a marked difference between methyl mercury poisoning and vascular disease. However, an abnormal Arden score is possible in cases with involvement at both parts of the cortices.

In any event the present method, especially the Arden grating test, was the most sensitive means to detect abnormality occurring in the visual system in connection with Minamata disease. Because of its simplicity, therefore, further clinical application will be useful in screening for methyl mercury poisoning.

This work was supported in part by grant No. 444063 from the Japanese Ministry of Education and grants from the Environment Agency, Japan, and from the Japanese Ministry of Health and Welfare.

\section{References}

1 Arden GB. The importance of measuring contrast sensitivity in cases of visual disturbance. $\mathrm{Br} J$ Ophthalmol 1978; 62: 198-209.

2 Arden GB, Jacobson JJ. A simple grating test for contrast sensitivity: preliminary results indicate value in screening for glaucoma. Invest Ophthalmol Visual Sci 1978; 17: 23-32.

3 Arden GB, Gucukoglu AG. Grating test of contrast 
sensitivity in patients with retrobulbar neuritis. Arch Ophthalmol 1978; 96: 1626-9.

4 Skalka HW. Comparison of Snellen acuity, VER acuity, and Arden grating scores in macular and optic nerve diseases. Br J Ophthalmol 1980; 64: 24-9.

5 Bodis-Wollner I, Diamond SP. The measurement of spatial contrast sensitivity in cases of blurred vision associated with cerebral lesions. Brain 1977; 99: 695710.

6 Tokuomi H, Okajima T, Kanai J, et al. Minamata disease. World Neurol 1961; 2: 536-45.

7 Hunter D, Russell DS. Focal cerebral and cerebellar atrophy in a human subject due to organic mercury compounds. J Neurol Neurosurg Psychiatry 1954; 17: 235-41.

8 Takeuchi T, Morikawa N, Matsumoto H, Shiraishi $\mathrm{Y}$. A pathological study of Minamata disease in Japan. Acta Neuropathol (Berl) 1962; 2: 40-57.

9 Skalka HW. Effect of age on Arden grating acuity. Br J Ophthalmol 1980; 64: 21-3.

10 Derefeldt G, Lennerstrand G, Lundh B. Age variations in normal human contrast sensitivity. Acta Ophthalmol (Kbh) 1979; 57: 679-90.

11 Kobayashi S, Tasaki Y, Ishikawa S, Mukuno K, Suzuki T. Spatial contrast sensitivity in cerebral lesions. Jpn Rev Clin Ophthalmol 1980; 6: 703-7. 